\title{
Visual perception in fencing: Do the eye movements of fencers represent their information pickup?
}

\author{
Norbert HagemanN \\ University of Kassel, Kassel, Germany \\ JÖRG SCHORER \\ Westfälische Wilhelms-University Münster, Münster, Germany \\ Rouwen CAÑAL-BRULAND \\ VU University Amsterdam, Amsterdam, The Netherlands \\ SIMONE LOTZ \\ Leibniz University Hannover, Hannover, Germany \\ AND \\ Bernd STRauss \\ Westfälische Wilhelms-University Münster, Münster, Germany
}

\begin{abstract}
The present study examined whether results of athletes' eye movements while they observe fencing attacks reflect their actual information pickup by comparing these results with others gained with temporal and spatial occlusion and cuing techniques. Fifteen top-ranking expert fencers, 15 advanced fencers, and 32 sport students predicted the target region of 405 fencing attacks on a computer monitor. Results of eye movement recordings showed a stronger foveal fixation on the opponent's trunk and weapon in the two fencer groups. Top-ranking expert fencers fixated particularly on the upper trunk. This matched their performance decrements in the spatial occlusion condition. However, when the upper trunk was occluded, participants also shifted eye movements to neighboring body regions. Adding cues to the video material had no positive effects on prediction performance. We conclude that gaze behavior does not necessarily represent information pickup, but that studies applying the spatial occlusion paradigm should also register eye movements to avoid underestimating the information contributed by occluded regions.
\end{abstract}

Because fencing is such a fast-moving sport, athletes are under enormous time pressure; as in racket sports, the time interval for preparing their own motor responses is so short that they have to anticipate their opponent's intentions (Azémar, 1999; Haase \& Mayer, 1978). Fencing coaches hypothesize that rapid responses to the opponent's actions are one of the major factors that determine level of performance (Roi \& Bianchedi, 2008). Because even world-class fencers do not have faster than average reaction times (see Di Russo, Taddei, Apnile, \& Spinelli, 2006; Harmenberg, Ceci, Barvestad, Hjerpe, \& Nyström, 1991), their performance advantage is thought to be due not just to physiological components (Roi \& Bianchedi, 2008) but also - and above all - to the ability to make better predictions about the intended target of a fencing attack by observing the opponent's preparatory phase (Azémar, 1999; Haase \& Mayer, 1978).
The goal of this study was to determine whether it is possible to ascertain the information fencers use in this anticipation process by analyzing eye movements. Accordingly, the fixation patterns of fencers observing fencing attacks were compared with results gathered in two other paradigms frequently used to determine information pickup in sports: the occlusion and cuing paradigms.

\section{Anticipation in Interactive Sports}

Early recognition of the action intentions of one's opponent leaves more time to prepare and carry out an appropriate reaction (Williams, 2009). This is a crucial aspect of the perceptual-cognitive expertise in interactive sports, as various temporal occlusion experiments have confirmed, particularly in racket sports (Mann, Williams, Ward, \& Janelle, 2007; Williams \& Ward, 2007). A typical temporal occlusion experiment stops a videotaped action

N. Hagemann, n.hagemann@uni-kassel.de 
sequence at a certain point in time, and the participant has to predict how it will continue. By presenting video sequences of varying duration from the perspective of a sport opponent, research has shown that experts can predict the action intentions of their opponents at an earlier timepoint in the movement sequence than novices can. This has been confirmed in badminton (Abernethy \& Russell, 1987a, 1987b; Hagemann \& Strauss, 2006), cricket (Müller, Abernethy, \& Farrow, 2006), soccer (Williams \& Burwitz, 1993), squash (Abernethy, 1990b), and tennis (Jones \& Miles, 1978). For example, Hagemann and Strauss (2006) used this paradigm to show that first- and second-division badminton players were already able to derive information about the potential landing point of a shuttlecock from the movement pattern of the stroke preparation 160-80 msec before racket-shuttlecock contact (see also Abernethy \& Russell, 1987a, 1987b). Although most findings based on the temporal occlusion technique possess limited ecological validity (due to the visual display and the atypical motor reaction for the sport), they match those from in situ experiments, in which the technique is implemented manually with liquid crystal occlusion glasses (e.g., Farrow \& Abernethy, 2003; Müller \& Abernethy, 2006; Müller et al., 2009).

However, little is known about which information is actually used to improve anticipation performance in each type of sport (Williams \& Ward, 2007). Alongside verbal reports (e.g., McRobert, Williams, Ward, \& Eccles, 2009), point light displays (Ward, Williams, \& Bennett, 2002), and biomechanical motion analyses (e.g., Huys, Smeeton, Hodges, Beek, \& Williams, 2008), past research has been based particularly on eye movement analyses and spatial occlusion experiments. These will be described in more detail below.

\section{Eye Movement Analyses}

An important indicator for describing visual information pickup is eye movements. This has been confirmed not only by numerous eye movement studies addressing a great variety of applied fields (e.g., aviation, road traffic) but also, and above all, by expert research in sport science. Generally, eye movement studies use special cameras to record fixation patterns during visual search for specific features of a presented scenario or image (the eye-tracking paradigm). The fixated locations should then reflect the areas of interest. Further quantitative measures such as the number of fixations and their duration are then related to the other information gathered in a study (Williams \& Ericsson, 2005). Using these features, numerous studies (for an overview in racket sports, see for example Cauraugh \& Janelle, 2002) have shown that experts use different visual search strategies compared with novices. Their task-specific knowledge structures seem to enable them to focus on more relevant areas of interest (Henderson, 2003; for an example, see Williams, Ward, Knowles, \& Smeeton, 2002). One frequent observation is that experts tend to perform fewer fixations of longer duration (for an overview, see Mann et al., 2007). However, such quantitative differences depend strongly on the task to be performed (Williams, Janelle, \& Davids, 2004). For example, Williams and Davids (1998) found ex- actly the opposite pattern in a one-on-one situation in soccer. In this task, experienced soccer players revealed more fixations of shorter duration than did less experienced soccer players (see also Bertrand \& Thullier, 2009).

Bard, Guezennec, and Papin (1981) also replicated this pattern in fencing. They used a portable NAC eyemovement measurement system to study three groups of fencers with different expertise levels in real-life fencing situations (competitions and training). As in Williams and Davids's (1998) soccer study, fencing masters and experts revealed shorter fixation durations than did novices. All three groups fixated predominantly on the hand guard $(37.8 \%)$, followed by the forearm $(21.4 \%)$. Among novices and experts, this was followed by the upper arm and, among the fencing masters, the trunk (14.8\%).

However, any interpretation of eye movement data must face one fundamental problem: the missing link between the registered fixation location and the extraction of information from this region ("looking" is not the same as "seeing"; see Williams \& Ericsson, 2005, p. 291). For example, by shifting attention it is possible to fixate on one specific region, while extracting information from neighboring regions in the periphery (Posner, 1980; Williams et al., 2004). Alongside such possible shifts of attention to pick up information (Hoffman, Nelson, \& Houck, 1983; Posner, 1980), it is also not yet known how much information is picked up, not just through the fovea, but also through parafoveal and peripheral regions of the retina (e.g., Abernethy, 1990b; Poulter, Jackson, Wann, \& Berry, 2005; Savelsbergh, Williams, van der Kamp, \& Ward, 2002). Gaze-contingent displays manipulating the size of the visible region surrounding the fixation point may permit quantitative estimates of this in future research (Schorer, Hagemann, Cañal-Bruland, Lotz, \& Strauss, 2010).

\section{Spatial Occlusion Technique}

Another way of ascertaining the regions from which athletes extract information is the spatial or event occlusion technique. This masks part of the information visible during the presentation (by either covering over an area or replacing it with the background). If the masking of a particular region leads to a deterioration in a participant's prediction performance, it would seem to be a region providing important information. For example, Abernethy and Russell (1987b) studied how precisely the landing point of a shuttlecock could be predicted, on the basis of videotaped badminton serves in which various regions were masked. During the serves, either the arm and the racket, only the racket, the head, the lower body, or background areas were masked with a black spot, so that the participant could not see them. Results showed that novices gained most of the important information for their predictions from the racket movement; top-ranking badminton players, in contrast, particularly used the arm and racket movement, but also fell back to some extent on head posture, lower body posture, and lower body motion. Interestingly, a comparison of the occluded and the nonoccluded video clips revealed no changes in eye movements. Further examples of the use of the spatial occlusion technique can be found in cricket (Müller et al., 2006), squash (Abernethy, 1990a), soccer 
(Williams \& Davids, 1998), and tennis (Jackson \& Mogan, 2007; Shim, Carlton, \& Kwon, 2006). By linking together temporal and spatial masking, it is also possible to determine the course of information pickup (e.g., Hagemann, Strauss, \& Cañal-Bruland, 2006).

Because it is easy to manipulate, the spatial occlusion technique has recently also been used with point light displays or stick figures (Abernethy \& Zawi, 2007; Abernethy, Zawi, \& Jackson, 2008). Huys et al. (2009) have applied it to ascertain the use of local dynamic information for anticipating tennis serves by manipulating the movement patterns of single body segments (see also Williams, Huys, Cañal-Bruland, \& Hagemann, 2009).

One problem here and in all spatial occlusion experiments is that the regions to be occluded are determined a priori. Because producing the video sequences is a lot of work and only a limited number of conditions can be implemented, such experiments can assess the importance of only a limited number of regions. Moreover, it is highly likely that experts do not base their predictions just on information from one isolated region, but tend to integrate information from several regions (Huys et al., 2009; Williams \& Ericsson, 2005).

\section{Combining the Spatial Occlusion Technique With Eye Movement Recordings}

Despite frequent calls to combine eye movement studies with, among others, the spatial occlusion technique (Williams \& Ericsson, 2005; Williams \& Ward, 2007), only Abernethy and Russell (1987b) and Williams and Davids (1998) have actually done this. Abernethy and Russell (1987b), for example, showed that, although there were no major differences in eye movements between experts and novices, the former were able to extract far more information from the movement patterns of badminton players. Abernethy (1990b, p. 74) concluded, "Information pick-up and visual search are clearly not identical." This study also showed that event occlusion manipulation had no impact on eye movements. Abernethy and Russell (1987b, p. 305) concluded, "This observation therefore supports in principle the capability of the event occlusion paradigm to make controlled comparisons of cue usage without causing the subject to elicit atypical or adaptive search patterns."

In the one-on-one situation in soccer described above, Williams and Davids (1998) studied not only eye movements (Experiment 1B) but also the impact of four spatial occlusion conditions on performance (Experiment 2B). Here as well, the pattern of eye movements did not reflect performance in the occlusion condition. However, because Experiment 2 did not control eye movements, and because the occlusion manipulation may have changed them, it is hard to make statements on actual information pickup.

\section{Cuing As a Further Option?}

Another possible way to assess relevant movement features that has received little attention in sport science up to now is cuing. Attention cues can be used in visual displays to direct participants' attention toward certain relevant features (Posner, 1980). Studies based on the cuing paradigm by Posner (1980) and colleagues (Posner, Nissen, \&
Ogden, 1978) have demonstrated that precuing the location at which a target stimulus is likely to appear facilitates performance on visual search and signal detection tasks (see Gottlob, Cheal, \& Lyon, 1999; Whitehead, MacKenzie, Schliebner, \& Bachorowski, 1997). Grant and Spivey (2003) highlighted single features in a static visual image to test whether this would help participants find the right answer to a problem-solving task (Duncker's radiation problem). They used pulsing to highlight the relevant features; that is, the breadth of a feature (in this case, a circle) fluctuated by one pixel three times a second. They concluded that manipulating attention through "a subtle increase in perceptual salience of a critical diagram component increased the frequency of correct solutions" (p. 465).

The positive impact of attention cues has also been confirmed in a perceptual learning study. Hagemann et al. (2006) studied how an attention cue in video clips influenced performance in predicting overhead serves in badminton. The attention cue was a transparent red patch that highlighted the main body regions (trunk, racket, and arm). Participants trained with the attention-cuing video clips showed a marked improvement in their predictions, as compared with a group trained without them. Directing attention toward the relevant body regions enabled novices to learn to anticipate the consequences of movement patterns more quickly (see also Cañal-Bruland, 2009a, 2009b; Kirlik, Walker, Fisk, \& Nagel, 1996).

Hence, at least for novices possessing little information on the distribution of important information in sport situations, highlighting relevant features with the cuing technique may well lead to a general increase in performance. Experts, in contrast, can be assumed to have already developed an optimal strategy for focusing attention through many years of training (Nougier \& Rossi, 1999). Nonetheless, cuing nonrelevant features should elicit a deterioration of prediction performance in both experts and novices.

\section{Research Question}

Because movements in fencing are so fast (less than 300 msec for a complete attack; see Harmenberg et al., 1991), one factor determining success is thought to be early recognition of the target region of the opponent's attacks. A comparison of experts and novices in a temporal occlusion experiment should confirm that experts can extract more information from the preparation for an attack. To determine which information is crucial when predicting the targets, we did not just analyze eye movements but simultaneously applied the spatial occlusion paradigm and the cuing technique to test whether the foveal fixations also corresponded in terms of information extraction.

\section{METHOD}

\section{Participants}

A total of 62 participants with differing fencing experience took part in the study. The expert group contained 15 athletes (12 male, 3 female) with a mean age of 20.36 years $(S D=4.63)$ and an average of 12.20 years $(S D=4.63)$ prior fencing experience. They were among the 60 top fencers in Germany (including Olympic champions, world champions, and German champions). At the time of the 
experiment, this group was completing an average of 5.37 training sessions per week $(S D=3.07)$. The advanced group contained 15 athletes ( 9 male, 6 female) who participated regularly in regional level competitions. Their mean age was 24.25 years $(S D=7.18)$, and they had an average of 12.09 years $(S D=5.12)$ of fencing experience. At the time of the experiment, this group was completing an average of 2.03 training sessions per week $(S D=1.21)$. The novice group contained 18 male and 14 female sport students. Their mean age was 24.70 years $(S D=2.66)$, and they had no prior experience of fencing. All participants provided informed consent prior to the study, which was conducted according to the ethical guidelines of the American Psychological Association (APA).

\section{Stimulus Materials}

Participants had to watch temporally occluded fencing attacks on a computer screen and predict the target region of the attacks. The stimulus materials were recorded at the University of Heidelberg with two right-handed males belonging to the top-60 épée fencers in Germany. ${ }^{1}$ As Figure 1 illustrates, the background was black, whereas the movement area was grayscale. The camera was positioned at normal human eye level in order to create the most representational perspective possible. Additionally, another top-60 fencer stood right next to the camera to act as the opponent in the filmed scenarios. Five different attacks (direct attack, angulation attack, and fleche attack; last two with sixte or quarte as defense response; see note 1) aimed toward five different target regions (right hand, right arm, body, right leg, and right foot) were recorded five times per fencer. These 250 video clips were then rated by an independent expert. The 30 video clips with the highest scores on ecological validity and technical appropriateness were chosen as the basis for each experimental condition. To ensure an equal distribution, we chose 10 direct attacks, 10 angulation attacks, and 10 fleche attacks (5 from each fencer). For the direct attack, each fencer performed an attack to the five target regions. In the last two conditions, the defense techniques were equally distributed, so that a sixte and a quarte defense technique (one by each fencer) were presented for each target region. In total, there were 6 different attacks to each of the five different target areas. These 30 clips were then temporally occluded at one $(40 \mathrm{msec})$, two $(80 \mathrm{msec})$, or three $(120 \mathrm{msec})$ frames before weapon impact. These 90 video clips were used in each experimental condition (see below). Videos were saved in AVI format $(25 \mathrm{~Hz})$ and had a resolution of $720 \times 576$ pixels. All videos were $1,800 \mathrm{msec}$ long.

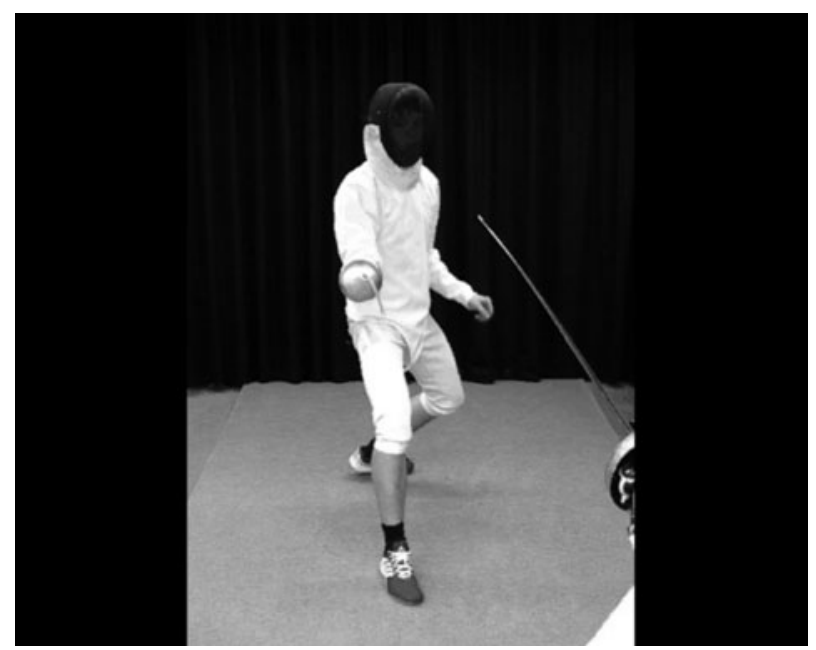

Figure 1. A still picture from the control condition. The participant sees the other fencer and the own weapon (on the right).

\section{Apparatus and Procedure}

All participants were seated approximately $50 \mathrm{~cm}$ in front of a 17-in. monitor (Iiyama VisionMaster Pro 510) with the seat height adjusted so that their eyes were approximately midscreen. Participants were given a brief introduction to the eye-tracking system, and they were fitted with a head-mounted Eyelink II system. This binocular eye-tracker recorded the eye movements at $500 \mathrm{~Hz}$. The ninepoint calibration was followed by a validation of this calibration.

In a first trial, participants watched 45 videos. For this set, 90 video clips were allocated at random to two control blocks while ensuring that variations in attack actions and temporal occlusion condition were distributed equally across the two conditions. The two conditions were counterbalanced across the participants. After the end of each video, participants saw a written list of the five possible target regions on the monitor and had to click the anticipated target region with the mouse. ${ }^{2}$

\section{Experimental Conditions}

Each participant had to complete one control block of 45 videos and one experimental block containing four conditions (two occlusion and two cuing conditions, see below) each containing 90 videos. This resulted in 360 experimental videos, so that participants watched a total of 405 short video clips. The sequence of blocks was balanced across participants.

Spatial occlusion. The study took account of the different procedures to be found in the spatial occlusion literature. To detect potential methodological differences, one condition masked the region in the visual display with a black circular spot, whereas the other condition replaced it with the background. Drawing on Bard et al. (1981) and further spatial occlusion experiments in other sports (e.g., Abernethy \& Russell, 1987b), we selected the following regions: head, trunk/attacking arm, upper legs, and lower legs/feet.

Spatial occlusion through masking. In these spatial occlusion tasks, a black circular spot was used to shadow the head, trunk/ attacking arm, upper legs, and lower legs/feet (see Figure 2). This spot was synchronized with the fencer's movements so that the region in question remained invisible throughout the trial. The size of the circle was the same in all conditions. In order to guarantee an equal distribution of the four body regions to the different videos, each of the 90 videos was provided with a black spot for each body region. These 360 videos were then distributed equally across four blocks while ensuring that the variations in attack actions and temporal occlusion condition were distributed equally across the four conditions. These four conditions were counterbalanced across participants. All experimental conditions were processed with the digital video processing program Adobe Premiere Pro 2.0.

Spatial occlusion by replacement with the background. In this spatial occlusion condition, the different body parts (head, trunk/ attacking arm, upper legs, and lower legs/feet) were erased and replaced with the background (see Figure 2). This condition also contained 90 videos.

Cuing. In this experimental condition, single body regions were highlighted with a transparent red patch (see Hagemann et al., 2006; Snowden, 2002). The position of the cue was synchronized with the position of the fencer in order to highlight one of the four body regions throughout the trial. As with the manipulations in the occlusion conditions, two methods were taken into account here as well: In one, regions were highlighted with a circular spot; in the other, they were covered by a transparent patch that highlighted only the body region in question and not other areas in the background (as is unavoidable with a circular spot). When producing all transparent patches and spots, care was taken to ensure that the highlighted regions remained highly visible (see Figure 2).

Cuing circle. Cues were the same size as the circular spots in the occlusion condition. They were transparent and accompanied the fencer's movement (see Figure 2). Ninety videos were presented in this condition as well.

Cuing body. This condition was identical to the occlusion condition, in which body regions were replaced by background, except that 

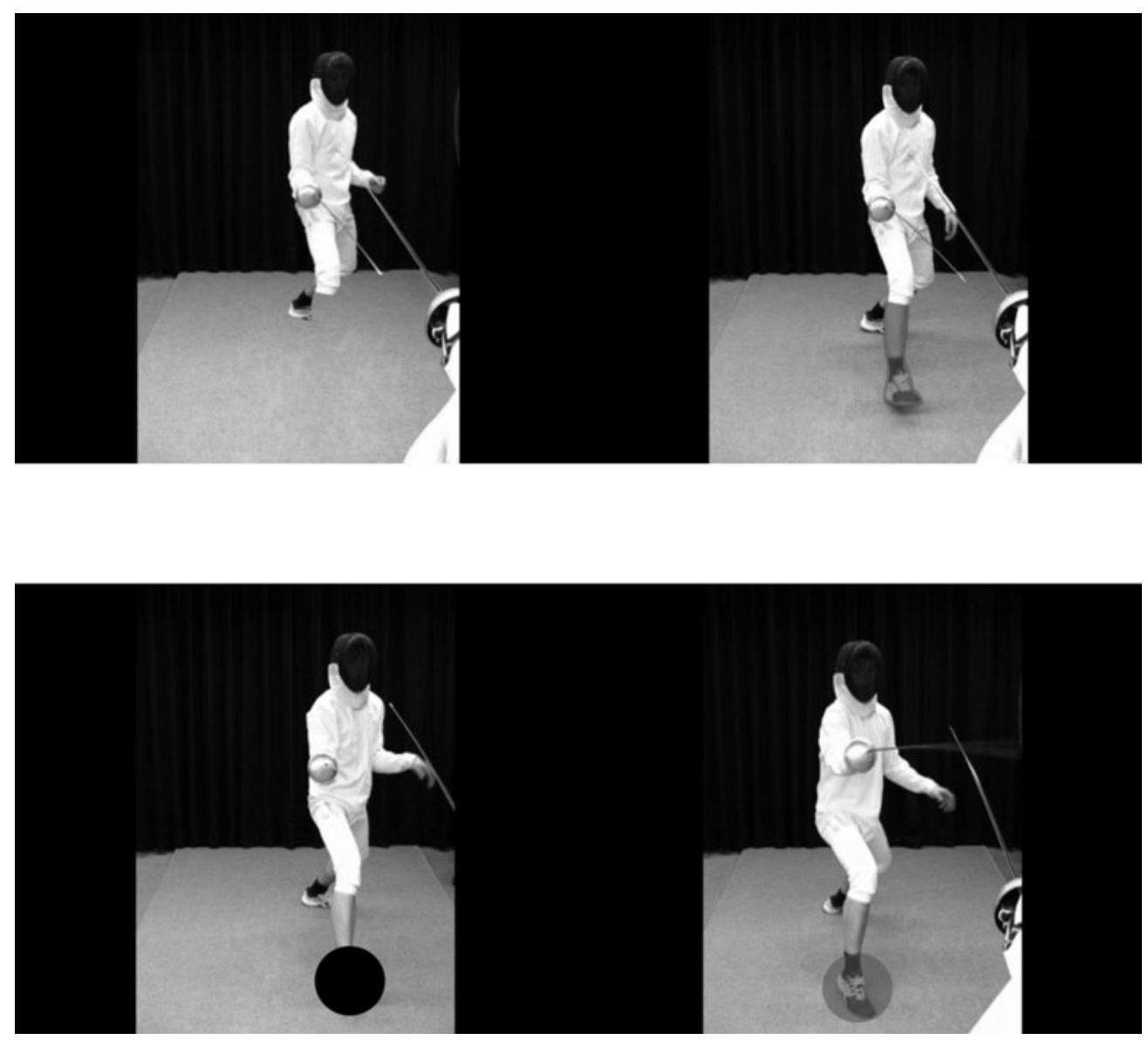

Figure 2. Sample frames from the four upper leg and lower leg manipulations. Top left: Spatial occlusion by replacement with background. Bottom left: Spatial occlusion by masking. Top right: Body cuing. Bottom right: Circular spot cuing.

the regions were highlighted with a transparent patch instead of being occluded (see Figure 2). Here as well, the regions were adjusted to follow the movements of the fencer. Ninety videos were presented.

\section{Data Analyses}

The first step was to analyze response accuracy. The dependent variable for all tasks was the percentage of correct predictions of the hit region out of five given possibilities. The second step used the eye-movement data to analyze viewing time on each region, relative fixation duration in milliseconds, and the number of fixations during the video clips. This used a frame-by-frame analysis, in which the fixation was aligned with a specially constructed analysis template for each single frame in the video material (see Figure 3). This procedure should have ensured a clear classification of the body regions. Finally, the fixation duration and the number of fixations were recorded.

The mean percentages of correct responses for each participant in each experimental condition and the eye movement data were subjected to a mixed repeated ANOVA. Alpha was set at .05 and effect sizes were calculated $\left(\eta_{\mathrm{p}}^{2}\right)$.

\section{RESULTS}

\section{Control Condition}

Prediction performance. Analysis of the 45 control videos presented as a block before the experimental phase showed that all three groups performed well above the guessing probability of $20 \%$. Experts attained a mean of $52.6 \%$ correct responses, followed by the advanced group with $M=47.0 \%$, and novices with $M=40.1 \%$. A mixed 3 (group) $\times 3$ (temporal occlusion point) $\times 5$ (target regions of attack) ANOVA with repeated measurement revealed a significant main effect of expertise level $[F(2,59)=6.54$, $\left.p<.05, \eta_{\mathrm{p}}^{2}=.18\right]$. A post hoc Scheffé test showed that both experts and the advanced group performed better than novices $(p<.05)$. There was also a main effect of temporal occlusion $\left[F(2,118)=11.96, p<.01, \eta_{\mathrm{p}}^{2}=.17\right]$. The more participants saw of the attack sequence, the better they could predict the target region of the attack $(120 \mathrm{msec}=$ $41.4 \% ; 80 \mathrm{msec}=47.0 \% ; 40 \mathrm{msec}$ of occlusion before weapon impact $=51.4 \%)$. This effect was independent of group $[F(4,118)=.35, p>.10]$. The target regions of the attacks revealed an interaction with temporal occlusion $\left[F(8,472)=3.70, p<.01, \eta_{\mathrm{p}}^{2}=.06\right]$ (see Table 1). Table 1 shows that with the increasing length of the video sequence, attacks on the legs and the feet in particular could be better predicted. The main effect of target region was also significant $\left[F(4,236)=1.54, p<.01, \eta_{\mathrm{p}}^{2}=.25\right]$. These effects were independent of group membership.

Eye movements. All 45 control videos from 21 randomly selected participants ( 8 experts, 7 advanced, and 


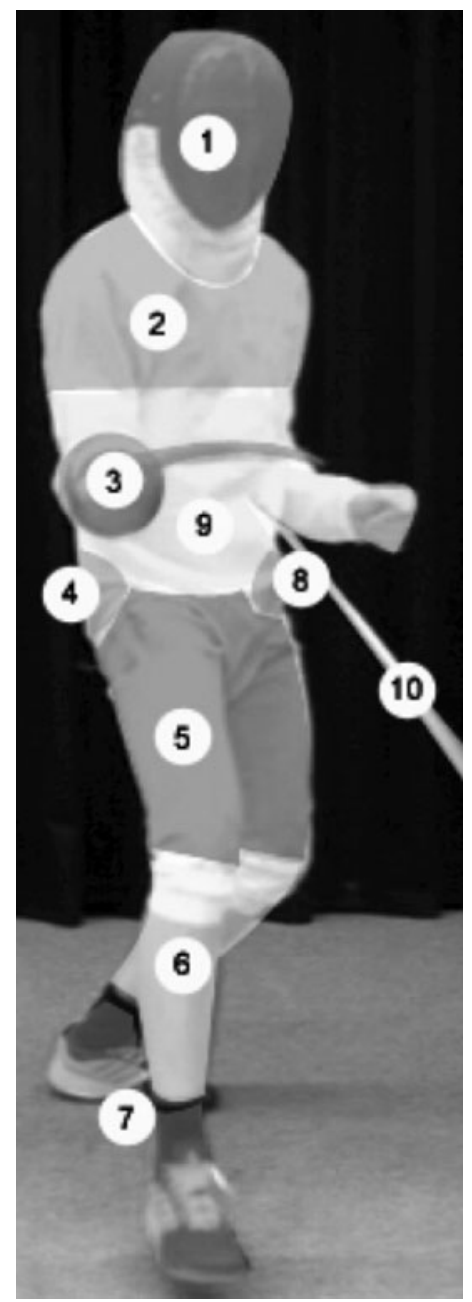

Figure 3. Analysis template for gaze fixations $(1=$ head; $2=$ upper trunk; $3=$ opponent's weapon; $4=$ left hip; $5=$ upper legs; $6=$ lower legs; $7=$ feet; $8=$ right hip; $9=$ lower trunk; and $10=$ own weapon).

6 novices) were subjected to a frame-by-frame analysis. ${ }^{3}$ The percentage distribution of observed body regions revealed a very strong focus on the upper body in all three groups (see Figure 4). The longest viewing times were on proximal regions, such as the lower trunk $(M=30 \%)$ and the opponent's weapon $(M=26 \%)$. Taken together, these accounted for more than $50 \%$ of the observed body regions. More distal regions, such as the lower legs $(M<1 \%)$, feet $(M<1 \%)$, and head $(M=1 \%)$, tended not to be the foveal focus in all three groups. An examination of the dif-

Table 1

Mean Percentage of Correct Predictions Depending on Temporal Occlusion Condition and Target Region in the Control Condition

\begin{tabular}{lccccc}
\hline & $\begin{array}{c}\text { Right } \\
\text { Hand }\end{array}$ & $\begin{array}{c}\text { Right } \\
\text { Arm }\end{array}$ & Body & $\begin{array}{c}\text { Right } \\
\text { Leg }\end{array}$ & $\begin{array}{c}\text { Right } \\
\text { Foot }\end{array}$ \\
\hline t-40 & 27.4 & 46.8 & 46.7 & 75.4 & 52.7 \\
t-80 & 35.9 & 36.6 & 54.3 & 54.3 & 41.9 \\
t-120 & 30.6 & 34.9 & 50.0 & 48.8 & 34.9 \\
\hline
\end{tabular}

ferences with a 3 (group) $\times 10$ (fixated body regions) ANOVA with repeated measures revealed a significant group $\times$ fixated body region interaction $[F(20,180)=$ $\left.2.35, p<.05, \eta_{\mathrm{p}}^{2}=.21\right]$. Experts fixated longer than the advanced group and the novices on the upper trunk region (both $p s<.05$ ). Novices fixated significantly longer on the upper legs than the either the experts or the advanced group (both $p \mathrm{~s}<.05$; see Figure 4).

A quantitative analysis of the characteristics of eye movements in all participants (univariate ANOVA) revealed no group differences in either the number of fixations $[F(2,56)=.50, p=.61$ (experts, $4.73 \mathrm{msec}$; advanced, $4.33 \mathrm{msec}$; novices, $4.49 \mathrm{msec})$ ], or their duration $[F(2,56)=0.67, p=.52$ (experts, $522.85 \mathrm{msec}$; advanced, $568.16 \mathrm{msec}$; novices, $508.70 \mathrm{msec})]$.

\section{Occlusion Condition}

A 3 (group) $\times 2$ (occlusion technique $) \times 4$ (target area $)$ ANOVA with repeated measures revealed no differences in prediction performance for the two occlusion techniques. Occluding the region with a circular spot did not produce any changes in response patterns, as compared with replacement by the background. Since there were no significant main and interaction effects (all $p \mathrm{~s}>.10$ ), both techniques were aggregated in further analyses.

Prediction performance. The 180 videos with occluded body regions (head, trunk, upper legs, and feet) also revealed a highly significant main effect of expertise level $\left[F(2,59)=15.34, p<.01, \eta_{\mathrm{p}}^{2}=.34\right]$. The post hoc Scheffé test showed that both experts $(M=54.7 \%)$ and the advanced group $(M=52.6 \%)$ made more correct decisions than did novices $(M=40.8 \%$; both $p \mathrm{~s}<.05)$.

A comparison of the two fencer groups with the novice group revealed a group $\times$ occluded region interaction $\left[F(2,180)=3.35, p<.05, \eta_{\mathrm{p}}^{2}=.05\right]$. Figure 5 reveals that occluding the trunk region led to a deterioration in predictions only in the fencer groups. The novices exhibited similar prediction performances for all occluded regions. The sharp declines in the fencer groups also explained the main effect of occluded regions $[F(3,177)=$ $\left.6.70, p<.05, \eta_{\mathrm{p}}^{2}=.10\right]$.

Eye movements. To analyze eye movements in the occlusion condition, all 90 videos of the background masking condition for the above-mentioned 21 randomly selected participants were subjected to a complete frame-by-frame analysis. The 2 (group) $\times 10$ (fixated body regions) $\times$ 2 (condition: control vs. occlusion) revealed a change in eye movements between the control condition and the occlusion condition $\left[F(10,160)=13.51, p<.05, \eta_{\mathrm{p}}^{2}=.46\right]$, but no significant differences between groups. Whereas no significant change in the regions observed could be found when head, legs, or feet were occluded, participants revealed different eye movements when upper and lower trunk regions were occluded (see Table 2). When the trunk was occluded, all groups shifted their gaze toward neighboring body regions (particularly the upper legs). After adjusting the $\alpha$ error, ${ }^{4}$ it could be seen that occluding the trunk led participants to shift their gaze significantly more to the upper legs $\left[F(1,16)=11.60, p<.05, \eta_{\mathrm{p}}^{2}=.42\right]$. At the same time, they looked significantly less at the op- 


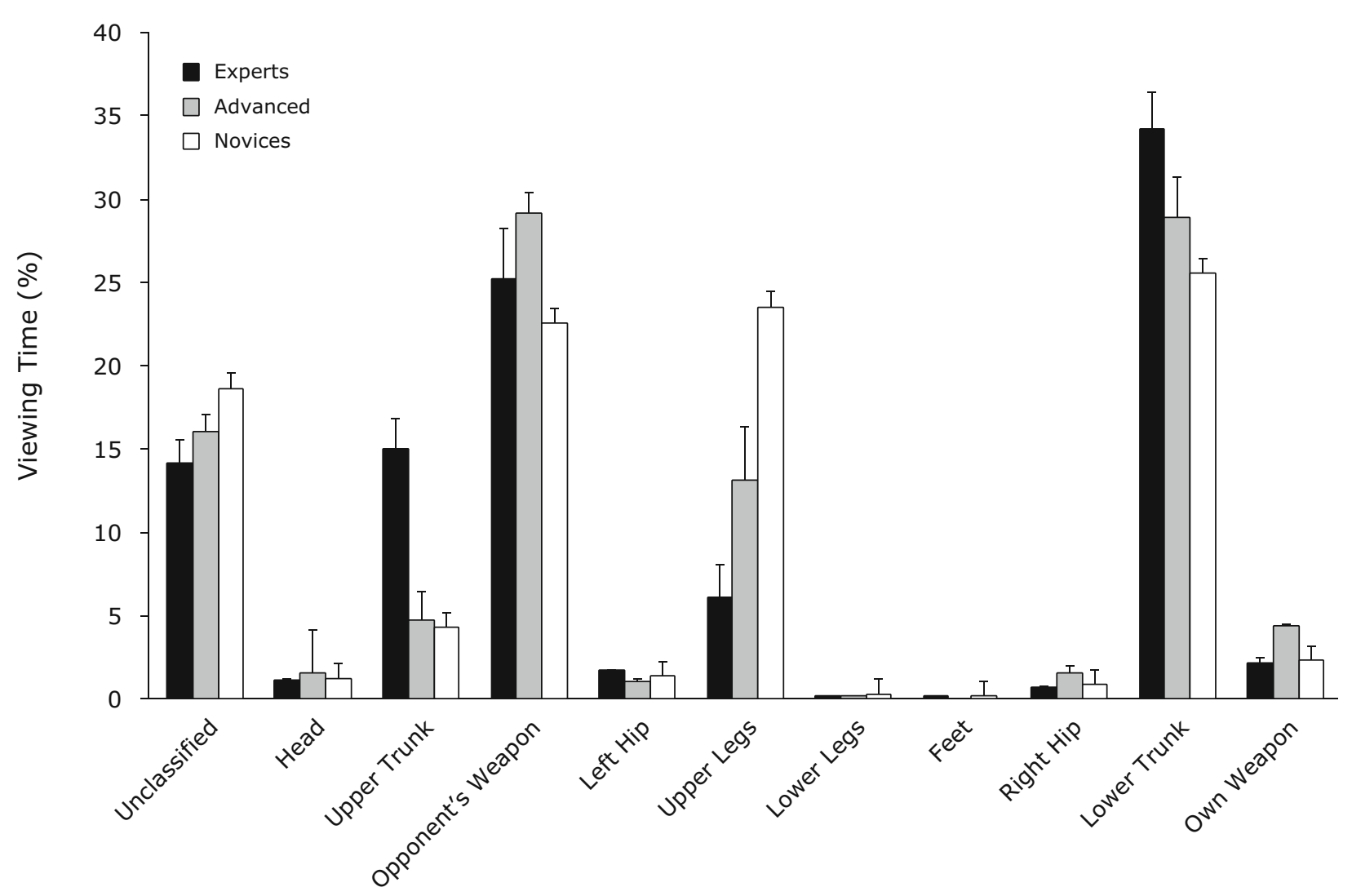

Fixation Location

Figure 4. Mean viewing time (in $\% \pm S E$ ) for the control videos in the three fencing groups.

ponent's weapon $\left[F(1,16)=37.15, p<.05, \eta_{\mathrm{p}}^{2}=.70\right]$, and at their own weapon $\left[F(1,16)=33.16, p<.05, \eta_{\mathrm{p}}^{2}=\right.$ .68]. However, after adjusting the level of $\alpha$ error, the increase in looking at the head was no longer significant $\left[F(1,16)=6.09, p>.05, \eta_{\mathrm{p}}^{2}=.28\right]$.
The quantitative analysis of eye movement data (univariate ANOVA) also revealed no significant group differences for either the duration $[F(2,56)=0.14, p=.87$ (experts, $515.62 \mathrm{msec}$; advanced, $535.36 \mathrm{msec}$; novices, $539.01 \mathrm{msec})]$, or the number of fixations $[F(2,56)=$

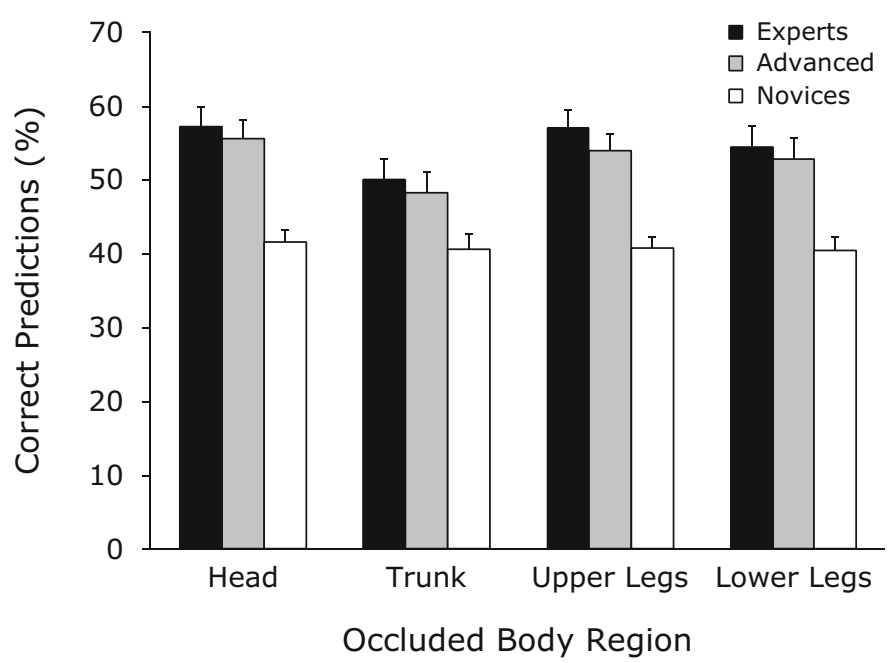

Figure 5. Mean number of correct predictions (in $\% \pm S E$ ) as a function of occluded body region and level of expertise. 
Table 2

Mean Percentage of Fixations on the Single Regions in the Experimental Conditions by All Three Groups

\begin{tabular}{|c|c|c|c|c|c|c|c|c|c|c|c|c|c|c|c|c|c|c|c|c|c|c|c|c|c|c|c|}
\hline & \multicolumn{9}{|c|}{ Experts } & \multicolumn{9}{|c|}{ Advanced } & \multicolumn{9}{|c|}{ Novices } \\
\hline & \multirow[b]{2}{*}{$\mathrm{CC}$} & \multicolumn{4}{|c|}{ Occlusion } & \multicolumn{4}{|c|}{ Cuing } & \multirow[b]{2}{*}{$\mathrm{CC}$} & \multicolumn{4}{|c|}{ Occlusion } & \multicolumn{4}{|c|}{ Cuing } & \multirow[b]{2}{*}{$\mathrm{CC}$} & \multicolumn{4}{|c|}{ Occlusion } & \multicolumn{4}{|c|}{ Cuing } \\
\hline & & $\mathrm{H}$ & $\mathrm{T}$ & $\mathrm{U}$ & $\mathrm{L}$ & $\mathrm{H}$ & $\mathrm{T}$ & $\mathrm{U}$ & $\mathrm{L}$ & & $\mathrm{H}$ & $\mathrm{T}$ & $\mathrm{U}$ & $\mathrm{L}$ & $\mathrm{H}$ & $\mathrm{T}$ & $\mathrm{U}$ & $\mathrm{L}$ & & $\mathrm{H}$ & $\mathrm{T}$ & $\mathrm{U}$ & $\mathrm{L}$ & $\mathrm{H}$ & $\mathrm{T}$ & $\mathrm{U}$ & $\mathrm{L}$ \\
\hline Unclassified & 14 & 14 & 12 & 13 & 14 & 13 & 14 & 13 & 12 & 16 & 15 & 13 & 16 & 16 & 18 & 19 & 17 & 18 & 19 & 17 & 12 & 16 & 16 & 17 & 17 & 17 & 20 \\
\hline Head & 1 & 1 & 4 & 1 & 1 & 1 & 1 & 1 & 2 & 1 & 3 & 5 & 2 & 1 & 2 & 1 & 1 & 2 & 1 & 7 & 14 & 6 & 1 & 6 & 6 & 5 & 7 \\
\hline Upper trunk & 15 & 9 & 13 & 6 & 8 & 15 & 14 & 11 & 13 & 5 & 9 & 9 & 4 & 6 & 6 & 6 & 6 & 5 & 4 & 10 & 12 & 9 & 6 & 8 & 9 & 8 & 6 \\
\hline Opponent's weapon & 25 & 24 & 8 & 23 & 25 & 27 & 26 & 29 & 28 & 29 & 20 & 8 & 27 & 28 & 24 & 26 & 25 & 25 & 23 & 21 & 8 & 24 & 29 & 19 & 20 & 20 & 18 \\
\hline Upper legs & 6 & 12 & 23 & 13 & 12 & 10 & 7 & 11 & 9 & 13 & 13 & 24 & 15 & 15 & 9 & 13 & 13 & 10 & 23 & 17 & 24 & 18 & 18 & 19 & 18 & 25 & 21 \\
\hline Lower legs & 0 & 0 & 0 & 1 & 0 & 0 & 0 & 0 & 0 & 0 & 0 & 0 & 0 & 1 & 0 & 0 & 0 & 0 & 0 & 1 & 0 & 1 & 0 & 1 & 0 & 1 & 1 \\
\hline Feet & 0 & 0 & 0 & 0 & 0 & 0 & 0 & 0 & 0 & 0 & 0 & 0 & 0 & 0 & 0 & 0 & 0 & 0 & 0 & 0 & 0 & 0 & 0 & 1 & 0 & 0 & 0 \\
\hline Right hip & 1 & 1 & 1 & 1 & 1 & 1 & 1 & 1 & 1 & 2 & 2 & 4 & 1 & 1 & 2 & 1 & 1 & 2 & 1 & 1 & 0 & 1 & 0 & 1 & 1 & 1 & 1 \\
\hline Lower trunk & 34 & 33 & 37 & 38 & 35 & 28 & 31 & 30 & 32 & 29 & 34 & 34 & 29 & 28 & 29 & 29 & 31 & 29 & 25 & 26 & 28 & 23 & 25 & 25 & 27 & 21 & 23 \\
\hline Own weapon & 2 & 1 & 0 & 1 & 2 & 2 & 2 & 0 & 2 & 4 & 2 & 1 & 4 & 4 & 5 & 2 & 3 & 5 & 2 & 1 & 0 & 3 & 2 & 2 & 2 & 1 & 3 \\
\hline
\end{tabular}

Note-CC, control condition; H, head; T, trunk; U, upper legs; L, lower legs.

$0.33, p=.71$ (experts, 4.47 msec; advanced, $4.18 \mathrm{msec}$; novices, $4.42 \mathrm{msec})$ ].

\section{Cuing Condition}

Similar to the spatial occlusion condition, data on the two cuing conditions (body region patch and circular spot) were aggregated. Although the 3 (group) $\times 2$ (cuing technique) $\times 4$ (target area) ANOVA with repeated measures revealed a main effect of cuing condition $[F(1,59)=5.31$, $\left.p<.05, \eta_{\mathrm{p}}^{2}=.08\right]$, indicating that cuing with a circle led to a deterioration in predictions, no interaction could be ascertained with the levels of expertise or the body regions (all $p \mathrm{~s}>.10$ ).

Prediction performance. The 180 videos in the cuing conditions also showed the anticipated expertise effect $\left[F(2,59)=11.71, p<.05, \eta_{\mathrm{p}}^{2}=.28\right]$, and the post hoc Scheffe test revealed that experts $(M=52.2 \%)$ and the advanced group $(M=48.6 \%)$ made significantly more correct decisions than novices $(M=42.5 \%$; both $p$ s $<.05)$. Nonetheless, it should be noted that the percentage of correct responses was very low in general, and, although not significant, below that found in the occlusion condition (see Table 3). ${ }^{5}$

There was also a significant main effect of body region $\left[F(3,177)=3.34, p<.05, \eta_{\mathrm{p}}^{2}=.05\right]$. In all three groups, cuing the feet $\left(M_{\text {feet }}=44.5 \%\right)$ led to poorer prediction performance than cuing the head region $\left(M_{\text {head }}=48.6 \%, p<\right.$ $.05)$ and trends toward poorer performance for the upper body $\left(M_{\text {upper body }}=46.0 \%\right)$ and the legs $\left(M_{\text {legs }}=46.7 \%\right)$.

Eye movements. As in the occlusion condition, all 90 videos in the cuing body condition for the 21 randomly selected participants were subjected to a complete frame-byframe analysis of eye movements in the cuing condition as well. The 2 (group) $\times 10$ (fixated body regions) $\times 2$ (condition: control vs. cuing) ANOVA revealed that the cuing conditions did not lead to changes in eye movements compared with the control condition $[F(10,160)=0.65, p>$ .10]. This was the case for each comparison between the control condition and the cuing conditions for head, trunk, upper legs, or feet. There were also no group-specific differences in changes in eye movements (see Table 2).

The quantitative analysis of eye movements (univariate ANOVA) also revealed no significant differences between groups in either the duration $[F(2,56)=0.80, p=.92$ (experts, $523.39 \mathrm{msec}$; advanced, $536.55 \mathrm{msec}$; novices, $521.20 \mathrm{msec})$, or the number of fixations $[F(2,56)=0.17$, $p=.84$ (experts, $4.24 \mathrm{msec}$; advanced, $4.13 \mathrm{msec}$; novices, $4.28 \mathrm{msec})$.

\section{DISCUSSION}

This study was designed to ascertain which information top-ranking fencers use to predict the direction of attacks. This expert-advanced-novice comparison focused on whether crucial information for this anticipation process as determined by analyzing eye movements would match results obtained with the occlusion and cuing techniques.

Because fencing movements are very fast (see, e.g., Harmenberg et al., 1991), early recognition of the target area of an opponent's attack is expected to be a factor determining performance (Azémar, 1999; Haase \& Mayer, 1978; Roi $\&$ Bianchedi, 2008). This was confirmed by the expertadvanced-novice differences in all experimental conditions. It was particularly top-ranking fencers who were able to extract markedly more information from temporally occluded video sequences and use this to predict the direc-

Table 3

Mean Percentage of Correct Predictions Depending on Condition (Occlusion vs. Cuing) and Level of Expertise

\begin{tabular}{|c|c|c|c|c|c|c|c|c|}
\hline & \multicolumn{4}{|c|}{ Occlusion } & \multicolumn{4}{|c|}{ Cuing } \\
\hline & Head & Trunk & $\begin{array}{l}\text { Upper } \\
\text { Legs }\end{array}$ & $\begin{array}{c}\text { Lower } \\
\text { Legs }\end{array}$ & Head & Trunk & $\begin{array}{l}\text { Upper } \\
\text { Legs }\end{array}$ & $\begin{array}{c}\text { Lower } \\
\text { Legs }\end{array}$ \\
\hline Experts & 57.2 & 50.0 & 57.1 & 54.5 & 55.2 & 51.4 & 52.5 & 49.7 \\
\hline Advanced & 55.5 & 48.3 & 54.0 & 52.8 & 49.9 & 48.8 & 49.0 & 46.8 \\
\hline Novices & 41.6 & 40.6 & 40.7 & 40.4 & 44.7 & 41.9 & 42.5 & 40.7 \\
\hline
\end{tabular}


tion of the opponent's attack. This is in line with not only the models described in fencing literature (Azémar, 1999; Haase \& Mayer, 1978; Roi \& Bianchedi, 2008), but also with findings from temporal occlusion experiments in other types of sport (Cauraugh \& Janelle, 2002). The high effect sizes in the expert-advanced-novice comparison suggest that this is an essential feature of perceptual-cognitive expertise in fencers (Williams, 2009). Moreover, it also seems to be a representative task with which to assess the underlying perceptual-cognitive mechanisms of fencing expertise in the laboratory (expert performance approach, see Williams \& Ericsson, 2005). The present study also revealed the typical findings from temporal occlusion experiments: the more the participants saw of the movement sequence, the better they could predict target regions. It is conspicuous that attacks directed toward lower body parts seemed to become recognizable only in longer video sequences.

Looking at the results of eye movements independently from the experimental manipulations, it can be seen that all three groups focused very strongly on the opponent's weapon and trunk. This corresponds to Bard et al.'s (1981) findings obtained with a portable NAC eye movement measurement system in real fencing situations. In the present study as well, foveal fixation was strong in the central regions but weak in distal regions. However, Bard et al. did not find the present study's strong fixation on the upper legs in novices. This may be due to, for example, differences in the measurement techniques (type of eyetracker) or the task (video based vs. in situ).

\section{Spatial Occlusion}

Integrating the results of the occlusion conditions into the analysis confirmed the importance of these regions for predicting attack targets. When the opponent's weapon and the upper body were occluded, fencers' prediction performance declined compared with the other occlusion conditions. In other words, it seems that important information was being extracted from the foveally fixated regions. As the novices' prediction performance did not change, it can be concluded that experts extract important information for predicting the attack target from the movements of the arm and the weapon and from movements of the upper body.

Occluding neighboring body regions might enable us to make statements about the degree of peripheral information processing. If a foveal fixation on the trunk region were to be accompanied by a deterioration due to the occlusion of neighboring regions (legs), this would be a sign of peripheral information processing. However, as the fixation locations changed in this study, we can make no statements about the peripheral information processing posited in the literature (e.g., Abernethy, 1990b; Poulter et al., 2005; Savelsbergh et al., 2002). Instead, the change in gaze behavior found here indicates that the spatial occlusion experiments reported in the literature have underestimated the importance of the occluded information. If information is now extracted from neighboring regions that would otherwise remain unused, this would result in a smaller decline in prediction performance. Because most studies (except for Abernethy \& Russell, 1987b) did not record eye movements, it was not possible to ascertain whether participants tried to extract information on the direction of an athlete's moves from other regions (Williams \& Ericsson, 2005). Williams and Davids (1998) also suspected that their participants might have tried to do this in the one-on-one situation in soccer reported above. They reported that although the experienced players in their Experiment 1B showed more foveal fixation on the hips, occluding this region (in Experiment 2B) did not affect their performance more than that of less experienced players. However, because the two variables were assessed separately, it was not possible to confirm this hypothesis. Williams and Ericsson (2005) interpreted the possible adaptation of information processing as an expression of perceptual flexibility, which may well be a further characteristic of top performance in sport. Huys et al. (2009) have presented an approach may help resolve this issue: a methodological modification of the spatial occlusion experiment that purposefully manipulates the movement pattern of single body segments instead of masking them completely (see also Williams et al., 2009).

However, even with this modification, the a priori specification of the regions to be studied is still a problem. Particularly in less well-studied sports, any a priori specification of potentially relevant regions is difficult. This applies to both the number and the size of the regions to be occluded. Moreover, it is necessary to consider quite generally that the isolated examination of single regions may lead to the loss of important information to be found at the transition to the occluded region (Ward et al., 2002). One possible solution might be to assess the additional utility of combining single regions into larger units (e.g., Müller et al., 2006).

At this point, it is necessary to mention two problems with the use of the occlusion technique in this study. First, the trunk occlusion condition covered a relatively large area that also contained the occlusion of the opponent's weapon. This obviously meant the loss of a great deal of relevant information for predicting the direction of attack. A further differentiation of the upper body regions into, for example, attack arm and trunk or chest region may well have been desirable. The occlusion of this large area may, in turn, have favored the change in eye movement. On the other hand, it is hard to decide on the basis of eye movements whether it is the opponent's weapon or the upper body that is currently being fixated. This is made particularly difficult through the continuous movement of the weapon and the way these areas are located one in front of the other. This difficulty, which is not found in other sports (e.g., "soccer penalty kick"; see Savelsbergh, van der Kamp, Williams, \& Ward, 2005), cannot be overcome in fencing. It must also have been a problem in Bard et al.'s (1981) in situ study. Future studies will have to search for ways to reduce the size of the occluded region in crucial body parts.

\section{Cuing}

The main finding from the cuing manipulation was that using transparent cues in video material had no positive effects on recognition performance. A comparison of the cuing conditions with the occlusion conditions reveals that although the average prediction performance did not 
differ significantly, it was even lower than that in the occlusion condition (see Table 3).

Looking at the results of the occlusion condition, it would seem plausible that cuing the trunk region would lead to better performance. This should be particularly the case for novices, because they still do not possess any adequate ideas as to which body regions are relevant. However, this was not the case. In general, there was a trend toward better performance when the head was cued, but this was still inferior to performance in the occlusion condition. On the other hand, the nonsignificant comparison with the control condition also means that an occlusion of specific body regions cannot be expected to lead to an improvement in prediction performance. Hence, in all three groups, cuing tended to be more of a distraction that impeded information pickup. Either the change in coloring or the change in contrast may mask relevant information (on the trunk). Highlighting nonrelevant regions (as ascertained through occlusion) may have led to a shift in information pickup that has also led to a deterioration in performance. The analysis of eye movements revealed no significant change in the regions observed. This suggests that participants had performed a covert shift (covert shift, Posner, 1980) in information pickup (Nougier, Stein, \& Azémar, 1990). The transparent patches may have had a distracting effect, particularly in the feet region, and impeded the processing of information from the upper body region. This would also fit Abernethy's (1990b, p. 74) notion that "visual search does not equal information extraction." Hence, gaze behavior in this cuing condition is a further indication that data from eye movement studies need to be interpreted with caution. Further research will need to ascertain how gaze behavior relates to information pickup in other contexts as well (e.g., tactile decision-making situations).

In sum, the findings presented here reveal that cuing is not an appropriate way to improve information pickup in an anticipation task and is actually more of a distractor. Similar results have also been reported for tactical decision-making situations with flicker cuing (CañalBruland, 2009a). It seems that cuing tends to distract in a test situation, and it only helps to effectively focus attention on relevant movement information when it is part of a long-term training program (e.g., Hagemann et al., 2006; Janelle, Champenoy, Coombes, \& Mousseau, 2003).

\section{CONCLUSION}

In summary, eye movement data and performance in spatial occlusion experiments show that fencing experts draw important movement information from the movement of the opponent's weapon or hand and trunk. The change in eye movement data highlights the weaknesses of spatial occlusion experiments and shows that when the spatial occlusion paradigm is used to assess information pickup, it is also desirable to record eye movements to be able to ascertain changes in gaze behavior. Nonetheless, further work needs to be directed toward ascertaining the relation between gaze behavior and information pickup. This will certainly also focus on the question of the role of peripheral information pickup (e.g., Schorer et al., 2010). Future research should also take further variables into account (e.g., one's own motor experience or situational probabilities) that could contribute to the eventual formulation of a comprehensive model depicting the basic principles of anticipation performance (e.g., Williams, 2009).

\section{AUTHOR NOTE}

This study was supported by a research grant from the German Research Foundation, code number STR 490/9-1 (GZ). We thank the German Olympic fencing centers (Olympiastützpunkt Fechten) in Tauberbischofsheim and Heidenheim for their support. Furthermore, we thank Jutta Behr for helping to produce the stimulus material. Additionally, we acknowledge Rebecca Rienhoff, Lennart Fischer, Nils Bender, JanMicha Hoekstra, Helge Bräutigam, and Florian Loffing for helping to prepare the stimuli and collect the data. Correspondence concerning this article should be addressed to N. Hagemann, University of Kassel, Institute of Sports and Sport Science, Heinrich-Plett-Str. 40, 34109 Kassel, Germany (e-mail: n.hagemann@uni-kassel.de).

\section{REFERENCES}

Abernethy, B. (1990a). Anticipation in squash: Differences in advance cue utilization between expert and novice. Journal of Sports Sciences, 8, 17-34.

Abernethy, B. (1990b). Expertise, visual search, and information pickup in squash. Perception, 19, 63-77.

Abernethy, B., \& Russell, D. G. (1987a). Expert-novice differences in an applied selective attention task. Journal of Sport Psychology, 9, 326-345.

Abernethy, B., \& Russell, D. G. (1987b). The relationship between expertise and visual search strategy in a racquet sport. Human Movement Science, 6, 283-319.

Abernethy, B., \& ZAWI, K. (2007). Pickup of essential kinematics underpins expert perception of movement patterns. Journal of Motor Behavior, 39, 353-367.

Abernethy, B., ZaWI, K., \& JACKson, R. C. (2008). Expertise and attunement to kinematic constraints. Perception, 37, 931-948.

AzÉmar, G. (1999). Le controle du mouvement dans les duels sportifs [Movement control in opposition sports]. Schweizerische Zeitschrift für Sportmedizin und Sporttraumatologie, 47, 68-70.

Bard, C., Guezennec, Y., \& PAPIn, J.-P. (1981). Escrime: Analyse de l'exploration visuelle [Fencing: Analysis of visual exploration]. Médecine du Sport, 55, 246-253.

Bertrand, C., \& Thullier, F. (2009). Effects of player position task complexity in visual exploration behavior in soccer. International Journal of Sport Psychology, 40, 306-323.

CAÑAL-BRULAND, R. (2009a). Guiding visual attention in decision making - Verbal instructions versus flicker cueing. Research Quarterly for Exercise \& Sport, 80, 369-374.

Cañal-Bruland, R. (2009b). Visual cueing in sport-specific decisionmaking. International Journal of Sport \& Exercise Psychology, 7, 450-464.

Cauraugh, J. H., \& Janelle, C. M. (2002). Visual search and cue utilisation in racket sports. In K. Davids, G. J. P. Savelsbergh, S. J. Bennett, \& J. van der Kamp (Eds.), Interceptive actions in sport (pp. 64-89). London: Routledge.

Di Russo, F., Taddei, F., Apnile, T., \& Spinelli, D. (2006). Neural correlates of fast stimulus discrimination and response selection in top-level fencers. Neuroscience Letters, 408, 113-118.

FArrow, D., \& Abernethy, B. (2003). Do expertise and the degree of perception-action coupling affect natural anticipatory performance? Perception, 32, 1127-1139.

Gottlob, L. R., Cheal, M., \& Lyon, D. R. (1999). Attention operating characteristics in a location-cuing task. Journal of General Psychology, 126, 271-287.

Grant, E. R., \& Spivey, M. J. (2003). Eye movements and problem solving: Guiding attention guides thought. Psychological Science, 14, 462-466.

HAase, H., \& MAYER, H. (1978). Optische Orientierungsstrategien von Fechtern [Optical orientation strategies in fencers]. Leistungssport, 8, 191-200. 
Hagemann, N., \& Strauss, B. (2006). Perzeptive Expertise von Badmintonspielern [Perceptual expertise in badminton players]. Zeitschrift für Psychologie, 214, 37-47.

Hagemann, N., Strauss, B., \& Cañal-Bruland, R. (2006). Training perceptual skill by orienting visual attention. Journal of Sport \& Exercise Psychology, 28, 143-158.

Harmenberg, J., Ceci, R., Barvestad, P., Huerpe, K., \& Nyström, J. (1991). Comparison of different tests of fencing performance. International Journal of Sports Medicine, 12, 573-576.

Henderson, J. M. (2003). Human gaze control during real-world scene perception. Trends in Cognitive Sciences, 7, 498-504.

Hoffman, J. E., Nelson, B., \& Houck, M. R. (1983). The role of attentional resources in automatic detection. Cognitive Psychology, 51, $379-410$.

Huys, R., Cañal-Bruland, R., Hagemann, N., Beek, P. J., SmeeTON, N. J., \& Williams, A. M. (2009). Global information pickup underpins anticipation of tennis shot direction. Journal of Motor Behavior, 41, 158-170.

Huys, R., Smeeton, N. J., Hodges, N. J., Beek, P. J., \& Williams, A. M. (2008). On the dynamic information underlying visual anticipation skill. Perception \& Psychophysics, 70, 1217-1234.

JACKSON, R. C., \& Mogan, P. (2007). Advance visual information, awareness, and anticipation skill. Journal of Motor Behavior, 39, 341-351.

Janelle, C. M., Champenoy, J. D., Coombes, S. A., \& Mousseau, M. B. (2003). Mechanisms of attentional cueing during observational learning to facilitate motor skill acquisition. Journal of Sport Sciences, 21, 825-838.

Jones, C. M., \& Miles, T. R. (1978). Use of advance cues in predicting the flight of a lawn tennis ball. Journal of Human Movement Studies, 4, 231-235.

Kirlik, A., Walker, N., Fisk, A. D., \& Nagel, K. (1996). Supporting perception in the service of dynamic decision making. Human Factors, 38, 288-299

Mann, D. Y., Williams, A. M., Ward, P., \& Janelle, C. M. (2007). Perceptual-cognitive expertise in sport: A meta-analysis. Journal of Sport \& Exercise Psychology, 29, 457-478.

McRobert, A. P., Williams, A. M., Ward, P., \& Eccles, D. W. (2009). Tracing the process of expertise in a simulated anticipation task. Ergonomics, 52, 474-483.

Müller, S., \& ABernethy, B. (2006). Batting with occluded vision: An in situ examination of the information pick-up and interceptive skills of high- and low-skilled cricket batsmen. Journal of Science \& Medicine in Sport, 9, 446-458.

Müller, S., Abernethy, B., \& Farrow, D. (2006). How do world-class cricket batsmen anticipate a bowler's intention? Quarterly Journal of Experimental Psychology, 59, 2162-2186.

Müller, S., Abernethy, B., Reece, J., Rose, M., Eid, M., McBean, R., ET AL. (2009). An in-situ examination of the timing of information pickup for interception by cricket batsmen of different skill levels. Psychology of Sport \& Exercise, 10, 644-652

Nougier, V., \& Rossi, B. (1999). The development of expertise in the orienting of attention. International Journal of Psychology, 30, 246-260.

Nougier, V., Stein, J. F., \& AzÉmar, G. (1990). Covert orienting of attention and motor preparation processes as a factor of success in fencing. Journal of Human Movement Studies, 19, 251-272.

Posner, M. I. (1980). Orienting of attention. Quarterly Journal of Experimental Psychology, 32, 3-25.

Posner, M. I., Nissen, M. J., \& Ogden, W. C. (1978). Attended and unattended processing modes: The role of set for spatial location. In H. L. Pick \& I. J. Saltzman (Eds.), Modes of perceiving and processing information. Hillsdale, NJ: Erlbaum.

Poulter, D. R., Jackson, R. C., Wann, J. P., \& Berry, D. C. (2005). The effect of learning condition on perceptual anticipation, awareness, and visual search. Human Movement Science, 24, 345-361.

RoI, G. S., \& BIANCHEDI, D. (2008). The science of fencing: Implications for performance and injury prevention. Sports Medicine, 38, 465-481.

Savelsbergh, G. J. P., van Der Kamp, J., Williams, A. M., \& Ward, P. (2005). Anticipation and visual search behaviour in expert soccer goalkeepers. Ergonomics, 48, 1686-1697.

Savelsbergh, G. J. P., Williams, A. M., van der Kamp, J., \& Ward, P. (2002). Visual search, anticipation and expertise in soccer goalkeepers. Journal of Sports Sciences, 20, 279-287.
Schorer, J., Hagemann, N., Cañal-Bruland, R., Lotz, S., \& Strauss, B. (2010). Contributions of foveal and peripheral vision to action anticipation-Field of vision does not influence anticipation training and retention, but transfer in fencing. Manuscript submitted for publication.

Shim, J., Carlton, L. G., \& Kwon, Y. H. (2006). Perception of kinematic characteristics of tennis strokes for anticipating stroke type and direction. Research Quarterly for Exercise \& Sport, 77, 326-339.

SNOWDEN, R. J. (2002). Visual attention to color: Parvocellular guidance of attentional resources? Psychological Science, 13, 180-184.

Ward, P., Williams, A. M., \& Bennett, S. J. (2002). Visual search and biological motion perception in tennis. Research Quarterly for Exercise \& Sport, 73, 107-112.

Whitehead, R., MacKenzie, T., Schliebner, S., \& Bachorowski, J. (1997). Effects of cue validity upon performance in the attention cueing paradigm. Perceptual \& Motor Skills, 84, 787-798.

Williams, A. M. (2009). Perceiving the intentions of others: How do skilled performers make anticipation judgments? In M. Raab, J. G. Johnson, \& H. R. Heekeren (Eds.), Mind and motion: The bidirectional link between thought and action (pp. 73-83). Amsterdam: Elsevier.

Williams, A. M., \& Burwitz, K. (1993). Advance cue utilization in soccer. In T. Reilly, J. Clarys, \& A. Stibbe (Eds.), Science and football II (pp. 239-244). London: Spon.

Williams, A. M., \& Davids, K. (1998). Visual search strategy, selective attention, and expertise in soccer. Research Quarterly for Exercise \& Sport, 69, 111-128.

Williams, A. M., \& Ericsson, K. A. (2005). Perceptual-cognitive expertise in sport: Some considerations when applying the expert performance approach. Human Movement Science, 24, 287-307.

Williams, A. M., Huys, R., Cañal-Bruland, R., \& Hagemann, N. (2009). The dynamical information underpinning anticipation skill. Human Movement Science, 28, 362-370.

Williams, A. M., Janelle, C. M., \& Davids, K. (2004). Constraints on the search for visual information in sport. International Journal of Sport \& Exercise Psychology, 2, 301-318.

Williams, A. M., \& WARD, P. (2007). Anticipation and decision making: Exploring new horizons. In G. Tenenbaum \& R. C. Eklund (Eds.), Handbook of sport psychology (3rd ed., pp. 203-223). Hoboken, NJ: Wiley.

Williams, A. M., Ward, P., Knowles, J. M., \& Smeeton, N. J. (2002). Anticipation skill in a real-world task: Measurement, training, and transfer in tennis. Journal of Experimental Psychology: Applied, 8, 259-270.

\section{NOTES}

1. Fencing terms for épée fencing: Three types of weapon are used in fencing: épée, foil, and saber. Compared to foil and saber, the target area in épée fencing is the entire body. Direct attack: a rapid attack directed toward a target area that ends as it begins. Angulation attack: a type of attack deviating around the defending weapon. Fleche attack: a surprise attack advancing on the opponent as rapidly as possible. Sixte and quarte defense response: one of the eight parries in the classical systems of épée fencing.

2. After answering the question on the target region, a second option field was presented in which participants had to select a motor action in response to this attack. Because this data did not relate to the present analysis, it is not reported here.

3. Participants were randomly selected from all three groups because of the large number of videos and the time-consuming nature of frameby-frame analysis.

4. The $\alpha$ error of .05 was divided by the number of tests performed $(N=11)$, resulting in an adjusted $\alpha$ error of .0045 .

5 . An additionally computed 3 (group) $\times 3$ (experimental condition: control, occlusion, and cuing) analysis revealed a main effect for the between-subjects factor group $\left[F(2,59)=20.48, p<.01, \eta_{\mathrm{p}}^{2}=\right.$ $.41]$. However, no effect could be confirmed for either the interaction $[F(4,118)=0.89, p>.10]$ or the experimental condition $[F(2,118)=$ $1.64, p>.10]$.

(Manuscript received November 20, 2009; revision accepted for publication June 15, 2010.) 